\title{
Genetic diversity of Rhizobium spp. isolated from soil samples of Bangladesh
}

\author{
Md. Tauhidul Islam Tanim ${ }^{1}$, Md. Miraj Kobad Chowdhury ${ }^{2}$, Latiful Bari³, Md. Mizanur Rahaman ${ }^{1}$, Sabita \\ Rezwana Rahman ${ }^{1}$ and Md. Majibur Rahman ${ }^{1 *}$ \\ ${ }^{1}$ Department of Microbiology, University of Dhaka, Dhaka-1000, Bangladesh; ${ }^{2}$ Department of Genetic Engineering and Biotechnology, University of Dhaka, \\ Dhaka-1000, Bangladesh; ${ }^{3}$ Centre for Advanced Research in Science (CARS), University of Dhaka, Dhaka-1000, Bangladesh.
}

\begin{abstract}
Rhizobia are Gram-negative soil-inhabiting bacteria commonly found in nodules of leguminous plants. These bacteria exclusively fix atmospheric nitrogen into ammonia, which is convertible to urea to serve natural fertilizer to the plants. However, rhizobial microbiota of Bangladesh have been studied poorly. Here, twenty isolates were identified as Rhizobium through observation of cultural characteristics, morphological characteristics and different biochemical tests. Isolates differed from one another in terms of their stress response characteristics like salt-stress tolerance, temperature tolerance, antibiotic susceptibility, and $\mathrm{pH}$. Most of the isolates were resistant to ampicillin and erythromycin and streptomycin; and were sensitive to kanamycin and ciprofloxacin. Isolates were clustered into three genotypic groups according to the banding patterns of Amplified Ribosomal DNA Restriction Analysis (ARDRA). All the strains in ARDRA group 1 were Rhizobium azibense, and the others were Rhizobium bangladeshense and Rhizobium qilianshanense. Future studies would validate their capacity of nitrogen fixation and the scope of improvement of these strains to increase their efficiency of nitrogen fixation.
\end{abstract}

Keywords: Rhizobium, biodiversity, stress response, ARDRA.

\section{Introduction}

Nitrogen is an essential nutrient for all living organisms and necessary to produce high-yield and high-quality agricultural crops $^{1}$. Nitrogen is one of the key atoms in amino acids, nucleotides, vitamins, co-factors, and various metabolites commonly found in living systems, as well as vital component of various drugs ${ }^{2}$. Although molecular nitrogen $\left(\mathrm{N}_{2}\right)$ is the most abundant gas in the atmosphere, no plant or animal can convert the atmospheric nitrogen to the metabolically active form of nitrogen (i.e. $-\mathrm{NH}_{2}$ or $-\mathrm{NO}_{3}$ ) ${ }^{3}$. Rhizobia are a genetically diverse and physiolo

gically heterogeneous group of soil inhabiting bacteria that have the capacity to form nodules on legume roots (and occasionally on stems) and can fix atmospheric nitrogen through a process called biological nitrogen fixation to partially or fully meet the nitrogen requirements of the host plant ${ }^{4}$. Such process contributes approximately $16 \%$ of total nitrogen input in crop land ${ }^{5}$. Thereby, Rhizobia are a major contributor in nitrogen fixation, and the legume-Rhizobium symbiosis can fix up to $450 \mathrm{Kg} \mathrm{N} / \mathrm{ha} / \mathrm{year}^{3,4}$.

Genetic and phenotypic diversity study helps to classify the variants of Rhizobium in different groups and to find efficient nitrogen fixing strain having desired traits ${ }^{6}$. The rhizobia from wild leguminous trees had been classified after extensive analysis of the phenotypic, genetic and molecular characteristics ${ }^{7}$. In another study, rhizobia from Acacia senegal and Prosopis chilensis, grown in Sudan, had been clustered according to the numerical analysis of phenotypic characteristics and lipopolysaccharide (LPS) profiles $^{8,9}$. Despite the identification of 74 rhizobial species to date including one new species from Bangladesh, few studies have been reported on the diversity of Rhizobium spp. of Bangladesh ${ }^{10,11}$. Since Bangladesh is a tropical country, the soil microbiota of this country is highly diversified ${ }^{12}$. Therefore, more studies are required to define such biodiversity, especially the diversity of rhizobial microbiota those are associated with nitrogen fixation.

This study was carried out with 20 rhizobial isolates from the nodules of seven leguminous plants species. These isolates were identified through morphological characteristics, biochemical tests, and partial 16S rDNA sequencing. Phenotypic diversity of the isolates was analyzed through observation of cultural characteristics, stress response characteristics and antibiotic sensitivity tests. Genetic diversity was analyzed by Amplified Ribosomal DNA Restriction Analysis (ARDRA). Thus, this study can be considered as a preliminary study on different rhizobial strains associated with nodules of these leguminous plants.

\section{Materials and Methods \\ Collection of soil samples}

Soil samples adjoining roots of seven different leguminous plants were collected from ten different regions of Bangladesh using sterile bucket trowel. The samples were sealed in sterile plastic bags and were carried to the laboratory. The leguminous plants include Caesalpinia pulcherrima, Delbergia sissoo, Lablab purpureus, Mimosa pudica, Moringa olefeira, Sesbania 
bispinosa, and Vigna unguiculata. The locations of sampling areas include Gazipur, Manikganj, Rajshahi, Mymensingh, Faridpur, Khulna, Patuakhali, Narsingdi, Sylhet and Chittagong districts.

\section{Isolation of rhizobial strains}

The soil samples were suspended in normal saline at 1:9 (w/v) ratios. The suspension was serially diluted and spread onto Congo Red Yeast Extract Manitol Agar (CRYEMA) medium ${ }^{13}$. Plates were then incubated at $30{ }^{\circ} \mathrm{C}$ for $24-48$ hours. Single colonies were isolated and pure cultures were obtained in CRYEMA plates. For long term storage glycerol stocks were prepared from the pure culture of the isolates. The stocks were kept at $4^{\circ} \mathrm{C}$ for $24-$ 48 hours followed by storage at " $20^{\circ} \mathrm{C}$.

\section{Morphological and biochemical characterization of rhizobial isolates}

Isolates were Gram stained and observed under both bright field microscope and Phase contrast microscope (Zeiss Primo Star, Germany). Biochemical tests that were performed included Catalase test, Indole production test, Methyl red test, VogesProskauer test, Citrate utilization test, Kliger's iron agar (KIA) test as described by Lowe; Motility test as mentioned by Arora and ONPG test (O-Nitrophenyl-D-Galacto-Pyranoside) with the protocols as described before ${ }^{14}$. The results of biochemical tests were observed after incubation at $30^{\circ} \mathrm{C}$ for $24-48$ hours.

\section{Stress response characteristics of rhizobial isolates}

To see the stress response characteristics, isolates were grown in Yeast Extract Mannitol Agar (YEMA) medium at different range of temperatures $\left(30^{\circ} \mathrm{C}-45^{\circ} \mathrm{C}\right)$, $\mathrm{pH}$ levels $(4.5-9.5)$ and salt $(\mathrm{NaCl})$ concentrations $(1 \%-4 \%(\mathrm{w} / \mathrm{v}))$. Following incubation at $30^{\circ} \mathrm{C}$ for 24-72 hours, growth of the isolates was observed. Antibiogram of the strains were performed using ampicillin $(10 \mathrm{mg})$, chloramphenicol (30 mg), ciprofloxacin $(5 \mathrm{mg})$, erythromycin (15 mg), kanamycin (30 mg), nalidixic acid (30 mg), rifampicin $(5 \mathrm{mg})$, and streptomycin $(10 \mathrm{mg})$ discs following the KirbyBauer disk diffusion method ${ }^{15}$. The zone diameters for individual antibiotics were translated to sensitive, intermediate and resistant categories by referring to Clinical \& Laboratory Standards Institute (CLSI) guidelines ${ }^{16}$.

\section{Molecular characterization}

DNA was extracted and purified from the isolates using standard phenol-chloroform-isoamyl alcohol method ${ }^{7}$. Quality and quantity of isolated DNA was measured by NanoDrop ${ }^{\mathrm{TM}}$ spectrophotometer (Thermo Fisher Scientific, USA). Approximately $1.5 \mathrm{~kb}$ of the $16 \mathrm{~S}$ rDNA gene of the isolates was amplified in a thermal cycler (Eppendorf Mastercycler ${ }^{\circledR}$, Germany) by PCR using the primers Forward: 52 AGAGTTTGATCMTGGCTCAG -32, and Reverse: 52 GGTTACCTTGTTACGACTT -32 . The PCR condition was: initial denaturation of 5 minutes at $95^{\circ} \mathrm{C}$ followed by 30 cycles of denaturation of 45 seconds at $94^{\circ} \mathrm{C}$, annealing of 45 seconds at $58^{\circ} \mathrm{C}$, extension of 2.5 minutes at $72^{\circ} \mathrm{C}$ with a final extension of 10 minutes at $72^{\circ} \mathrm{C}$. The PCR products were electrophoresed in a $1 \%$ agarose gel containing ethidium bromide and observed under UV transilluminator. For amplified rDNA restriction analysis (ARDRA), the PCR products were digested overnight with AluI (Thermo Fisher Scientific, USA) restriction enzyme. After agarose gel electrophoresis on $1.5 \%$ gel containing ethidium bromide, the resulting digested products were visualized on a UV transilluminator. For sequencing, the PCR product was sent to FirstBase Malaysia and the sequences were processed using FinchTV. The sequences were blasted at NCBI, and were also analyzed using MEGA v6.0.

\section{Results and Discussion}

The importance of rhizobial species identification particularly stands on the increasing demands of biofertilizers for organic farming. Also, the methods and typical morphological and cultural characteristics of nodulating rhizobial strains have been standardized $^{17}$. It is reported that inoculation of indigenous rhizobial strains in soil increases the fertility of soil as well the agricultural production ${ }^{18}$. To understand the rhizobial diversity of soil samples of Bangladesh, we have successfully isolated 20 strains capable of producing moderate to large colonies on CRYEMA medium. Among them, 16 showed pinkish colonies and the remaining 4 showed whitish colonies. These four isolates produced copious amount of extracellular polysaccharide (EPS). All the isolates were Gram negative rod-shaped, non-spore-forming and motile bacteria (Figure 1A and 1B). They were able to utilize citrate as a source of energy, and positive for catalase and b-galactosidase activities. Also, these strains were non-fermentative, do not produce acetoin and hydrogen sulfide, and negative for typtophanase, urease, and gelatinase activities. All these findings indicated that the isolated strains were rhizobial strains ${ }^{19-21}$.

Salinity intrusion has a common effect on food crops, livestock, and fish species of Bangladesh and the response to such stress are diverse in microbial community ${ }^{22}$. In addition to that, response to other stress like temperature, $\mathrm{pH}$, and antibiotics are highly variable among the rhizobial species ${ }^{17}$. Changes in these stresses are one of the limiting factors to restrict the efficiency of nitrogenfixation in legume-rhizobia symbiotic association ${ }^{23}$. In our study, we have observed that all the isolates were able to grow on $2 \%$ (w/v) $\mathrm{NaCl}$, at $30-33{ }^{\circ} \mathrm{C}$, and within the $\mathrm{pH}$ range 6.5-7.5. However, the growth declined with the increased salt concentration (Figure 2A). Only 2 isolates were able to tolerate $4 \%(\mathrm{w} / \mathrm{v}) \mathrm{NaCl}$. This kind of salt tolerance is similar to the previous studies ${ }^{24}$. Growth of the isolates were also inhibited with an increase or decrease of $\mathrm{pH}$ from 6.5-7.5, except the same two isolates (Figure 2B). The growth of the isolates hindered when the temperature is increased, and none of the isolates could tolerate temperature above $45^{\circ} \mathrm{C}$ (Figure 2C). 16 out of the 20 strains were resistant to ampicillin and erythromycin, and 15 strains showed resistance to rifampicin and streptomycin. However, all these strains were sensitive to ciprofloxacin and nalidixic acid, and 18 strains were sensitive to chloramphenicol and kanamycin (Figure 2D). All these data indicated that the 


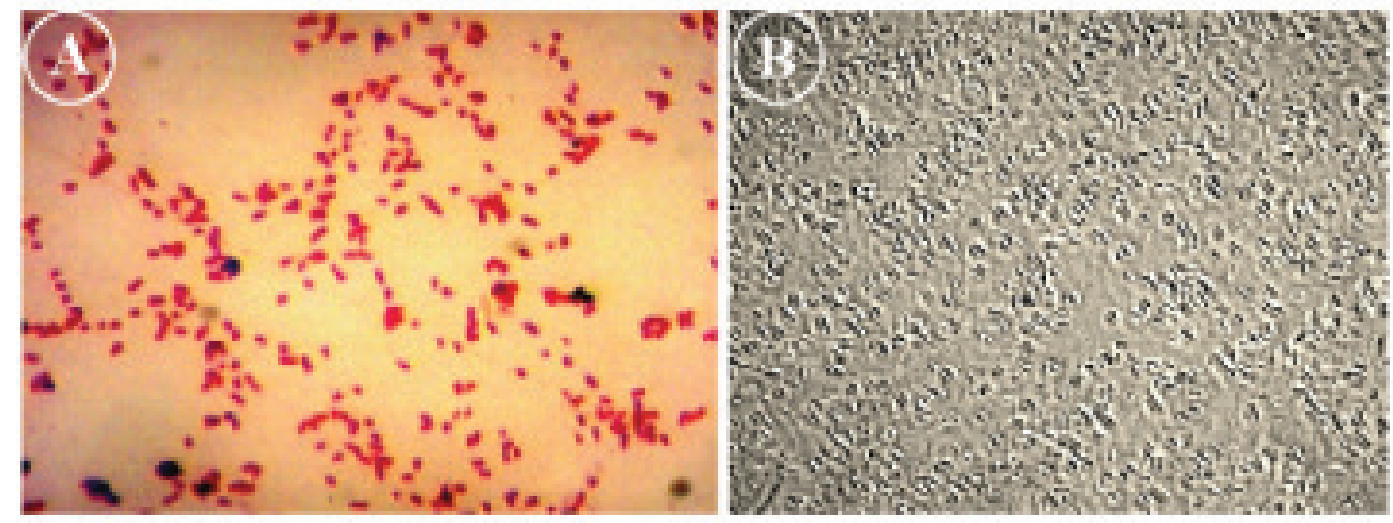

Figure 1. Representative microscopic images of the rhizobial isolates at 100X. (A) Gram staining revealed that they were Gram negative. (B) Phase contrast microscopic image of the isolates.
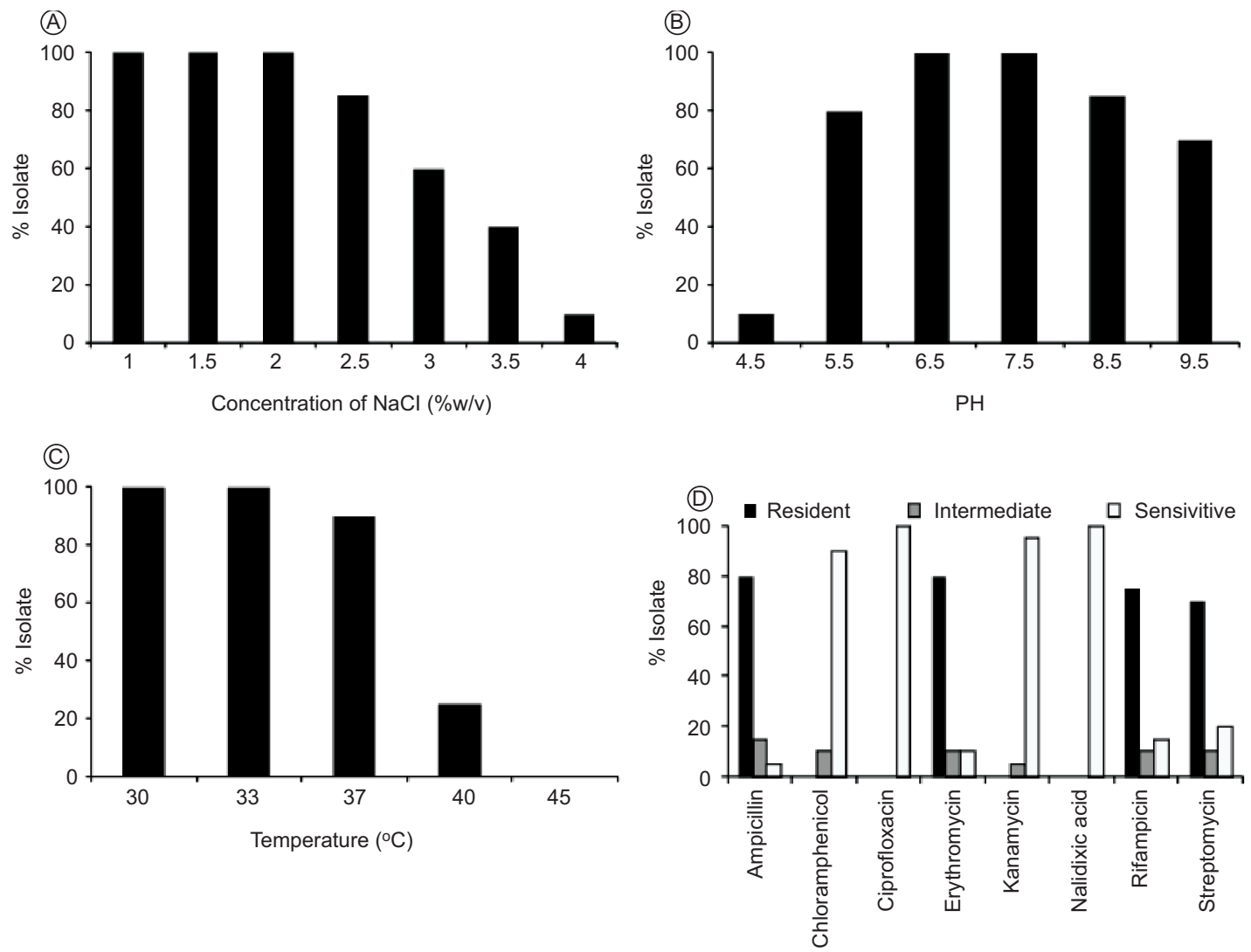

Figure 2. Stress tolerance of the isolates. Individual isolates were grown in (A) different concentrations of $\mathrm{NaCl}$, (B) different $\mathrm{pH},(\mathrm{C})$ different temperature, and $(D)$ in presence of different antibiotics.

isolated strains were diverse in response to salt, temperature, acid, and antibiotic stresses.

16S rDNA sequencing is a powerful tool for the identification of microbial species ${ }^{25}$ and we have identified our isolated rhizobial strains by $16 \mathrm{~S}$ rDNA genotyping. For this, Universal primers (also known as primers 27F and 1492R) were used to partially amplify the $16 \mathrm{~S}$ rDNA. The expected PCR product of around $1.5 \mathrm{~kb}$ was observed in case of all isolates (Figure $3 \mathrm{~A}$ ). The PCR products were subjected to sequencing to identify the species, and also the amplified rDNA restriction analysis (ARDRA) to define the genetic diversity. The digestion of 16S rDNA PCR products by Alu 1 for ARDRA indicated 3 genotypic groups. ARDRA group 1 consisted of 18 isolates. Of the two remaining isolates, one was in ARDRA Group 2 ( $R$. bangladeshense) and the other one was placed in ARDRA group 3 (R. qilianshanense) (Figure 3B) revealed these strains were of three ARDRA groups with group 1 consisting of 18 strains. Partial 16S rDNA sequence analysis revealed that these 18 strains belong to Rhizobium azibense. The remaining two strains were Rhizobium bangladeshense and Rhizobium qilianshanense. These $R$. bangladeshense and $R$. qilianshanense were isolated from the soil samples adjoining the root of Caesalpinia pulcherrima and 


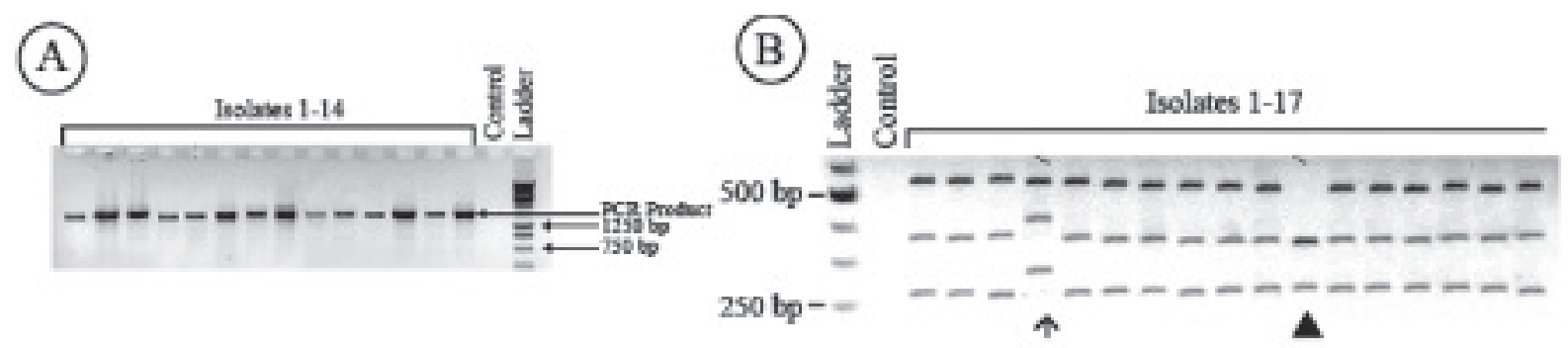

Figure 3. Amplification of partial $16 \mathrm{~s} r D N A$ and ARDRA of the isolates. (A) Partial $16 \mathrm{~s}$ rDNA was amplified using universal primer. (B) Three distinct ARDRA pattern was observed confirming three rhizobial species.

Lablab purpureus respectively. These observations indicated that the rhizobial species mostly associated with the nodules of different legumes is Rhizobium azibense and the rhizobial community in the tested soil samples were genetically less diverse.

\section{Acknowledgement}

We gratefully acknowledge the financial contribution of the Ministry of Education and Ministry of Science and Technology, GOB to carry out this research work. We would also like to thank the Department of Microbiology, University of Dhaka, Dhaka-1000 and Centre for Advanced Research in Science (CARS), University of Dhaka, Dhaka-1000 for their co-operation during this research.

\section{References}

1 Johnston AE. 1994. The role of nitrogen in crop production and losses of nitrate by leaching from agricultural soil. Marine Poll. Bulletin. 29: 414-419.

2 Tarselli MA. 2012. Life and death with nitrogen. Nature Chemistry. 4: 686.

3 Ollivier J, Towe S, Bannert A, Hai B, Kastl EM, Meyer A, Su MX, Kleineidam K and Schloter M. 2011. Nitrogen turnover in soil and global change. FEMS Microbiol. Ecol. 78: 3-16.

4 Unkovich MJ and Pate JS. 2000. An appraisal of recent field measurements of symbiotic $\mathrm{N}_{2}$ fixation by annual legumes. Field Crops Res. 65: 211-228.

5 Chen J, Shen W, Xu H, Li Y and Luo T. 2019. The composition of nitrogenfixing microorganisms correlates with soil nitrogen content during reforestation: a comparison between legume and non-legume plantations. Frontiers Microbiol. 10: 508.

6 Zahran HH. 1997. Chemotaxonomic characterization of some fast-growing rhizobia nodulating leguminous trees. Folia Microbiologica. 42: 367-380.

7 Naveed M, Mubeen S, Khan S, Ahmed I, Khalid N, Suleria HA, Bano A and Mumtaz AS. 2014. Identification and characterization of rhizospheric microbial diversity by $16 \mathrm{~S}$ ribosomal RNA gene sequencing. Bra. J. Microbiol. 45: 985-993.

8 Zhang X, Harper R, Karsisto M and Lindström K. 1991. Diversity of rhizobium bacteria isolated from the root nodules of leguminous trees. Int. J. Syst. Evol. Microbiol. 41: 104-113.

9 Nick G, de Lajudie P, Eardly BD, Suomalainen S, Paulin L, Zhang X, Gillis M and Lindstrom K. 1999. Sinorhizobium arboris sp. nov. and Sinorhizobium kostiense sp. nov., isolated from leguminous trees in Sudan and Kenya. Int. J. Syst. Bacteriol. 49: 1359-1368.

10 Rashid MH, Young JP, Everall I, Clercx P, Willems A, Santhosh Braun M and Wink M. 2015. Average nucleotide identity of genome sequences supports the description of Rhizobium lentis sp. nov., Rhizobium bangladeshense sp. nov. and Rhizobium binae sp. nov. from lentil (Lens culinaris) nodules. Int. J. Syst. Evol. Microbiol. 65: 3037-3045.
11 Shamseldin A, Carro L, Peix A, Velazquez E, Moawad H and Sadowsky MJ. 2016. The symbiovar trifolii of Rhizobium bangladeshense and Rhizobium aegyptiacum sp. nov. nodulate Trifolium alexandrinum in Egypt. Syst. Appl. Microbiol. 39: 275-279.

12 Saha M, Islam M, Binta Aziz C and Hossain Z. 2012. Molecular identification of bacteria present in the soils of the Madhupur Sal and the Sunderban mangrove forests of Bangladesh. Dhaka Univ. J. Biol. Sci. 21: $127-123$.

13 Kneen BE and Larue TA. 1983. Congo red absorption by Rhizobium leguminosarum. Appl. Environ. Microbiol. 45: 340-342.

14 Cappuccino JG and Sherman N. 2016. Microbiology: a laboratory manual. 11th edn. Pearson Ltd.

15 Bauer AW, Kirby WM, Sherris JC and Turck M. 1966. Antibiotic susceptibility testing by a standardized single disk method. Am. J. Clin. Pathol. 45: 493-496.

16 Jorgensen JH and Hindler JF. 2007. New consensus guidelines from the Clinical and Laboratory Standards Institute (CLSI) for antimicrobial susceptibility testing of infrequently isolated or fastidious bacteria. Clin. Infect. Dis. 44: 280-286.

17 Torres-Gutiérrez R, Granda-Mora KI, Alvarado-Capó Y, Rodriguez AS, Mogollón NGS and Almeida JRD. 2017. Genetic and phenotypic diversity of Rhizobium isolates from Southern Ecuador. Ciência. Agrotecnol. 41: 634-647.

18 Bello SK, Yusuf AA and Cargele M. 2018. Performance of cowpea as influenced by native strain of rhizobia, lime and phosphorus in Samaru, Nigeria. Symbiosis. 75: 167-176.

19 Panwar A, Choudhary S, Sharma M, K Shrama Y, Meena RS, Malhotra S, S Mehta R and Aishwath O. 2013. Morphological and biochemical characterization of Rhizobium isolates obtained from fenugreek (Trigonella foenum). Seed Res. 40: 196-200.

20 Kapembwa R, Mweetwa A, Ngulube M and Yengwe J. 2016. Morphological and biochemical characterization of soybean nodulating rhizobia indigenous to Zambia. Sustain. Agri. Res. 5: 84-92.

21 Purushottam, Shruti, Tyagi C, Tomar A, Kumar R, Dhyani BP and Poonia S. 2017. Isolation and biochemical characterization of Rhizobium from root nodules of mungbean (Vigna radiata). Int. J. Plant Res. 30: 505-507.

22 Alam MZ, Carpenter-Boggs L, Mitra S, Haque MM, Halsey J, Rokonuzzaman M, Saha B and Moniruzzaman M. 2017. Effect of salinity intrusion on food crops, livestock, and fish species at Kalapara coastal belt in Bangladesh. J. Food Quality. 2017: 1-23.

23 Berrada H, Nouioui I, Iraqui Houssaini M, Ghachtouli NE, Gtari M and Fikri Benbrahim K. 2012. Phenotypic and genotypic characterizations of rhizobia isolated from root nodules of multiple legume species native of Fez, Morocco. African J. Microbiol. Res. 625: 5314-5324.

24 Abdelmoumen H, Filali-Maltouf A, Neyra M, Belabed A and El Idrissi MM. 1999. Effect of high salts concentrations on the growth of rhizobia and responses to added osmotica. J. Appl. Microbiol. 86: 889-898.

25 Woo PC, Lau SK, Teng JL, Tse H and Yuen KY. 2008. Then and now: use of $16 \mathrm{~S}$ rDNA gene sequencing for bacterial identification and discovery of novel bacteria in clinical microbiology laboratories. Clin. Microbiol. Infect. 14: 908-934. 